\title{
Rectitud, Responsabilidad, Solidaridad
}

\author{
Por el Doctor PEDRO PABLO GUTIERREZ F.
}

\section{Sumario.}

La Rectitud.-Rectitud y responsabilidad.-Sentido de responsabilidad.Elementos subjetivos.-Elementos objetivos.-Las tres zonas de la responsabilidad.-Ia voluntad de Dios expresada en la naturaleza.-Papel del hombre. -Principios de la solidaridad.-Aplicación de los principios.

\section{La Rectitud.}

La rectitud es un ideal que debe inspirar, arientar y dominar la conducta del hombre; para Séneca era una virtud omniperfecta, absoluta y autónoma, rectitud propia del sabio estoico -que "tal vez aparece cada quinientos años" - y describe asi la semblanza del hombre recto, al propio tiempo sabio y gobernante:

"Un alma que contempla lo verdadero, experta en lo que se debe evitar $y$ apetecer, no según la opinión sino según la naturaleza, compenetrada en todo el mundo, presente con su mirada a cuanto en él se hace, tensa en el pensar y el obrar. tan grande como esforzada, invulnerable a la esperanza $y$ al halago, superior a los vaivenes de fortuna, destacada sobre lo contingente $\mathrm{y}$ accidental, bellísima, ordenadísima por su gracia y su fuerza, sana y enjuta, imperturbable, intrépida, inquebrantable a la violencia, ni engreída ni abatida por el azar. Esa alma es la virtud. Esta es su faz, mirada de golpe $y$ presentada de una vez" (1).

Esta posición estoica favoreció a la moral autónoma de Kant; el imperativo categórico atribuye al hombre, ser compuesto y finito, perfecciones absolutas y autónomas que sólo existen en Dios, acto puro, simplísimo $Y$ omniperfecto.

(1) Ep., 66.6. 
Aspiramos, en realidad, a virtudes que no sean imposibles. La experiencia diaria contradice las anteriores tesis $\mathrm{y}$ corrige las pretensiones de la autonomía humana. La filosofía cristiana acepta los hechos históricos y reconoce que la rectitud absoluta y autónoma. es atributo exclusivamente divino. La rectitud humana es imitación de la de Dios; no es absoluta, sino limitada, deficiente, variable; puede perfeccionarse, pero también degenerar y perderse. Y esta variabilidad de la rectitud humano hace necesaria la ley eterna, fuente de toda ley; y con la ley, el sentido de la responsabilidad.

\section{Rectitud y responsabilidad.}

Por una triple vía desemboca el tema de la rectitud en el sentido de la responsabilidad.

Primera vía es la metafísica. Nuestra variabilidad moral es signo de contingencia, y como tal ser, el hombre depende de Dios. La rectitud. divina es fundamento $\mathrm{y}$ origen de la humanidad, rectitud de Padre $\mathrm{y}$ de Juez; la nuestra es la del servicio debido a Dios. Cuando el hombre vislumbra su capacidad de servir y adaptarse a la rectitud infinita de Dios, comienza a estar dominado por el sentido de la grave responsabilidad que es el gozar del libre arbitrio.

Una segunda vía une la rectitud con la responsabilidad a través de las tendencias sociales innatas en el hombre. La rectitud es virtud esencialmente social, exigida en las relaciones con el Creador y con nuestros seme. jantes (2). Pero no es cualidad tan innata como el instinto social humano - el gregario de los animales. Para favorecer el nacimiento de la rectitud, y protegerla contra la natural tragilidad humana, Dios nos ha querido proveer con el sentido de la responsabilidad, defensa poderosa de la rectitud, cuando ésta no se considera como virtud absoluta y autónoma.

Y el tercer camino es el de la ley. Sin la ley eterna, la obra de la Creación se perdería en el Caos del desorden. Pero toda ley supone sujetos capaces de cumplirla. Es para sujetos rectificables. $Y$ sin el sentido de la responsabilidad, el hombre no sería rectificable ni sujeto de ley (3).

\section{Sentido de responsabilidad.}

El sentido de la responsabilidad es una cualidad esencial de la persona; algo real y necesario para la vida juridico-moral, no sólo una noción elaborada par la filosotía. Cada hombre recibe de él un germen

(2) Este aspecto social fué desconocido en la moral autónoma griega, Sócrates I Platón no concretaron su interés en el hombre como individuo ni en los intereses universales de la humanidad; en la moral aristotélica notamos la presencia de principios incompatibles con ol sentido de la responsabilidad. Kant construye la sociedad humana con las tendepcias antisociales del hombre, superándolas, a fin de llegar a un equitibrio colectiro.

(3) Por ello, la posición estoica no entendió al sentido de la responabulitad. Ni fué capaz de admitirlo lógicamente la moral Kantiana. Ni puedo aceptarlo el individualismo liberal, pues libertad interna absoluta y responsabilidad son dos conceptos que se excluyen. Y todo sistema totalitario es igualmente contrario al sentido de la responsabilidad. 
para orientarse rectamente. $A$ cada uno en particular, y a la ciencia en general, toca su ulterior desarrollo, que adquiere infinitas variedades de diferenciación e intensidad. Definía Suớrez el sentido de la responsabilidad como la capacidad con que el hombre se adapta racionalmente a las condiciones de la vida de solidaridad; capacidad y condiciones que ofrecen una variedad tan inmensa, que sería imposible hallar dos hombres con sentido de responsabilidad igualmente desarrollado; otro tanto ocurre en las culturas y filosofías, registrándose orientaciones objetivistas y subjetivistas, más o menos unilateralmente fomentadas. Assí, Platón y Aristóteles propenden hacia un objetivismo poítico; los estoicos, en cambio, fomentaron el aspecto social eminentemente vitalista, inspirado en la acción universal del logos (4).

Ambas corrientes han influído en los moralistas cristianos. El aspecto social vitalista estoico fué elevado al orden sobrenatural. La Teología moral escolástica estudia el principio interno regulativo de la conducta en su aspecto más objetivo, como dictamen práctico del entendimiento,o como juicio último o definitivo de la moralidad de los actos; a ésto se endereza la doctrina escolástica sobre la formación de la conciencia. Pero tampoco descuidaron el aspecto más subjetivo del conocimiento y desarrollo del sentido de la responsabilidad; la Moral y el Derecho deben ocuparse de cultivar la capacidad de amar rectamente y disponer al hombre para el cumplimiento de sus obligaciones. Y, aún más, han admitido la necesidad de sintetizar ambos aspectos (5).

El sentido de la responsabilidad se eleva y se perfecciona cuando el hombre conoce las relaciones especiales en que le coloca la solidaridad universal humano-divina en la que debe tomar parte activa como servidor de Dios, como hijo suyo y hermano de sus semejantes. Las exigencias de perfeccionamiento individual social y política deben elevarse para que el hombre sea capaz de esta vida superior, a la que está llamado en forma inexcusable.

\section{Elementos subjetivos.}

Fácilmente inferimos de lo dicho, que en el sentido de la responsabilidad cabe distinguir tres elementos: el subjetivo, el objetivo, el social.

Elemento subjetivo básico es la advertencia al mundo jurídico-moral. En el acto moral hay dos notas que faltan en el simplemente voluntario: la

(4) En base a datos tomados de la literatura y costimbres de numerosos pueblosno stempre con exactitud- se ha hundado una orientación objetivista, concretada por Faucon. not. (La responsabilité, Etude de Sociologie, París 1920); la escuela subjetiva, al contrario.. sáto ad̀mite un carácter individual en los tenómenos de responsabilidad, o por lo menos lo atribuye la primería entre los alementos que la integran; pero no aduce pruebas on cuanto al carácter exclualivo y cerrado que atribuye a la responsabilidad personal.

(5) En particular, Suárez desarrolló un estuerzo no igualado para lograr dicha sintesis.. con la doctrina sobre la justicia de Dios, informada por la creencia de que Dios Creadorio Padre y logillador ha querido lormar con el hombre una verdadera sociedad. 
advertencia o cierta previsión de las consecuencias de dicho acto en el mundo jurídico-moral, y la libertad del acto (6).

Con la primera comienza la zona de la responsabilidad (7). No basta la capacidad de querer - ni aún la de querer con libertad psicológicapara ser sujeto responsable de las acciones; esa libertad radical imperfecta no basta para hacer dueños de los actos.

Una vez que se liegue al pleno uso de la razón y de la libertad radical perfecta, ya es el hombre capaz de responsabilidad, aunqus ésta será leve, si el uso de la libertad es imperfecto. Para que haya sentido de responsabilidad, debe ser perfecta la libertad $y$ la vis deliberativa; es decir, la voluntad y la razón deben estar perfectamente desarolladas.

Empieza el sentido de la responsabilidad con el uso imperfecto de la libertad, en una zona intermedia entre la capacidad de obrar libremente y el uso perfecto de la libertad. Basta para tener alguna responsabilidad cierto conocimiento inicial de la obligación. Usar perfectamente de la libertad supone por su parte la plena advertencia al orden jurídico-moral, con la intuición propia del sentido moral, el cual, por lo mismo, necesita una nota más que el sentido de la responsabilidad, pues incluye cierto juicio virtual sobre las cosas agibles y vitandas, y cierto criterio de conducta no sólo para sí, sino también para poder juzgar las acciones de los demás. Puede uno sentirse responsable sin poseer todavía tales criterios e intuiciones. Luego, el sentido moral es una cualidad más evolucionada, reflexiva y universal que el comienzo del sentido de responsabilidad. En el desarollo del hombre aparecen, sucesivamente, la libertad, el sentido de la responsabilidad, el sentido moral y el proceso de formación de la conciencia. Tales son los elementos subjetivos que aparecen progresivamente en la actividad jurídico-moral del hombre.

Con la educación progresiva del sentido moral, el sentido de la responsabilidad se fortalece y perfecciona, y ambos, a su vez, con la práctica $y$ desarrollo de la conciencia, de manera que vienen a confundirse trecuentemente los términos de sentido de responsabiildad, sentido moral y conciencia. Importa subrayar que tanto en los primeros atisbos del sentido de responsabilidad como en su colaboración en las últimas determinaciones de la conciencia, la actitud subjetiva del hombre tiende necesariamente a conformarse a exigencias objetivas, que entran en lo que podemos llamar con término general la advertentia rationis.

\section{Elementos objetivos.}

Entre las exigencias objetivas a que la razón debe advertir, la primera y tundamental es la dependencia esencial que como consecuencia de la Creación, tiene la creatura respecto del Creador. Hay una estrecha correla-

(6) Cfr. Sućrez, De actu morali I 2.5:4.284: "El ser moral no añade a la sustancia del acto voluntario más que cierto modo de emanación o motal dependencia de la razón que advierte, y de la libertad con que obra la voluntad".

(7) De otra manera, se define el sentido de la responsabilidad como la capacidad para darse cuenta de las repercusiones del acto en el mundo jurídico-moral. 
ción entre la dependencia entitativa y la dependencia jurídica establecidas por el hecho de la creación, de suerte que cuando la creatura es más perfecta, mayor es su dependencia. Así, Dios, como principio del ser, es también el principio del Derecho. Mas, aún prescindiendo de la voluntad divina, de la misma naturaleza de las cosas nace cierta obligación natural de obrar rectamente, en virtud de la sujeción natural del hombre a Dios

Y si éstas son obligaciones reales que se deducen de la consideración de la creatura en sí, de hecho Dios ha estrechado sus relaciones con ella, estableciendo con la Encarnación del Verbo, una Providencia amorosa, constituyendo al hombre dentro de un estatuto juridico sobrenatural: la justicia divina. Y los lazos jurídico-sociales, naturales $y$ sobrenaturales, que en el reino de la justicia de Dios entrelazan al hombre con el creadar, forman en la actual providencia, el mundo jurídico-moral. A cada hombre corresponde un puesto determinado en este complejo e inmenso mundo. Su sentido natural de responsabilidad, cultivado por la educación y la experiencia, le sirve para ajustar su conducta a los seres que integran ese mundo con su variada interacción de las causas físicas y morales.

\section{Ias tres zonas de la responsabilidad.}

En base al sentido ético, social y religioso que tiene cada persona para la conservación de los valores humanos particulares y colectivos, podemos considerar una triple zona en el sentido de la responsabilidad (9).

El sentido moral tiende al perfeccionamiento individual del hombre en sus valores específicamente humanos, el cual sólo puede conseguirse en la vida social, juntamente con la perfección de las tendencias sociales; ésto es consecuencia de la solidaridad humana. Entre el bien humano individual y el social no hay oposición, sino armonía; no podríamos aspirar al desarrollo completo de nuestro yo razonable sin el concurso de los demás, en la sociedad de la que formamos parte (10).

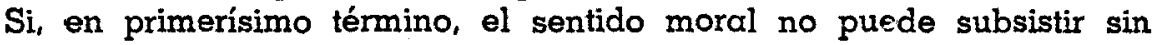
cierto conocimiento de Dios como Causa primera de la obligación moral, éste mismo conocimiento implica la alteridad Creador-creatura, que lleva consigo un sentido de sociabilidad. Ni puede darse un conocimiento propio de la persona sin un sentido social, pues la nota de alteridad es tan esencial al concepto de persona como la individualidad. A diferencia de los irracio-

(8) Este raciocinio supone haber puesto Dios en la naturaleza racional cierta fuerza perceptiva. Es necesario para la rectitud de las costumbres, que si Dios tiene la voluntad de mandar al hombre, éste se ha de conformar con ella.

(9) Se podría, tal vez, añadir una cuarta dimensión an los valores juridicos, en sí diversos de los éticos y sociales. pero que para los cfectos perceptibles del sentido de la responsabilidad, se confunden prácticamente con los morales $Y$ sociales.

(10) Tal idea de la solidaridad recíproca se funda en la identidad específica humana (Gillet, La educación del carácter, trad. Cunchillos; Buenos Aires, 1946, pp. 117-183. También la invocó Cicerón para apoyar la existencia de le ley natural idéntica para todos los hombres. Todo hombre normal necesita de los demás, Y es necesario también para los suyos por lax solidaridad que con ellos tiene. 
nales, el hombre recibe las impresiones del mundo sensible, no actuando necesariamente a sus estímulos, sino que las elabora, las domina, y toma la iniciativa para reaccionar socialmente a los requerimientos del mundo externo, es decir, a los seres con quienes se siente ligado necesariamente por el entendimiento y la voluntad. Esta constitución superior de la personalidad humana se manifiesta en el funcionamiento de sus facultades; la mente del hombre no posee sólo un conocimiento pasivo y directo de las cosas, sino también conocimientos indirectos $y$ periscópicos, que le ponen en relación con seres presentes y ausentes, con hechos pasados y futuros, que la hacen capaz del sentido ético-social propio de su sustancia racional.

Vemos, de este modo, que la solidaridad individual y social, con sus derechos y obligaciones, supone por lo menos el vislumbre de una solidaridad y de una sumisión religiosa respecto a la Causa primera de los seres. Sin algún conocimiento, por lo menos virtual y confuso de la divinidad, el sentimiento del deber sería una ilusión bastante fácil de desenmascarar.

\section{La voluntad de Dios expresada en la naturaleza.}

Mas tampoco basta un conocimiento puramente subjetivo, indicium rationis, para la solidaridad propia del sentido de la responsabilidad, que supone la capacidad de dialogar con las cosas. Estas no pueden hablar por sí mismas; pero pueden captar la voz de Dios, registrarla en el seno de su naturaleza, y reproducirla cuando se les pregunte por la voluntad del Creador. La inadvertencia a esa voz supone sordera, distracción o aletargamiento en el sentido de la responsabilidad (11).

Hay una perceptividad estricta de la ley natural; la naturaleza de las cosas no sólo sirve para indicar la voluntad indirecta de Dios, sino para dar a conocer su expresa voluntad de mando $y$ de gobierno. Dios habla, pues, en la naturaleza de las cosas, en ellas manda y prohibe, imponiendo su voluntad de conservar y promover la solidaridad religiosa, moral y social, triple aspecto de las exigencias que constituyen la solidaridad universal.

\section{Papel del hombre.}

A estas exigencias se adapta el hombre con más o menos perfección, según su sentido de responsabilidad. En el aspecto religioso y moral. la falta o poco desarrollo de tal sentido pueden sustituírse con una esmerada educación, que debidamente inculque el amor a Dios; pero también puede lograrse, por la misma vía, el honor debido a los padres, el respeto a la vida y al pudor propio y ajeno, a los bienes y fama del prójimo.

Es, sin embargo, en el aspecto social donde la eficacia de la edu. cación más fácilmente falla, y el sentido de responsabilidad es el factor

(11) La voz de Dios que se percibe en la naturaleza no es, como han pretendido algunos teólogos, una metáfora o consideraciones de nuestra mente más o menos objetivamente fundadas; tal explicación seria adversa I destructora del concepto de la ley natural. 
principal para conocer en concreto el respeto debido a las personas morales y costumbres públicas, el valor de las instituciones jurídicas, sociales $y$ culturales. Hay personas moral y religiosamente intachables, que al mediar las pasiones políticas, pierden el freno por faltarles el sentido de responsabilidad o adaptación a las exigencias de solidaridad; les falta comprensión para los valores de la justicia general o social, que forman la trama social de las relaciones humanas; practican en lo posible una caridad afectiva, pero no la vinculativa (12). El sentido de responsabilidad que no se base en una alteridad de relaciones con un último sujeto activo de exigencias y requerimientos, es algo así como un Código legal sin legislador y $\sin$ poder ejecutivo y judicial; es una construcción ideal, sin aplicación $\alpha$ la realidad, por lo menos en forma eficaz.

Aunque no en forma igual, el sentido de responsabilidad atiende a las exigencias de esta triple solidaridad. Moral y religiosamente no admite limitaciones ni restricciones. En cambio, las responsabilidades sociales pueden ser limitadas por justos motivos de bien común, si bien no arbitraria ni totalmente: es injusto el legislador o gobernante que, sin verdadera necesidad, se arroga a sí mismo las responsabilidades sociales que incumben $\alpha$ los ciudadanos, sometiéndolos a una minoriedad arbitraria, que en casos extremos podría equivaler a pérdida de ciudadanía.

Sin apenas darnos cuenta, va surgiendo en nuestra mente la persuación de encontrarnos estrechamente unidos en nuestra actividad y destino al resto del Universo. Es que la naturaleza de las cosas ayuda a conocer algunas conexiones fácilmente observables; y a ello ayudan la cercanía de las personas con quienes se vive, la simultaneidad con que se repiten ciertos actos sociałes, la mutua indigencia de los hombres y la interdependencia general de los seres. No obstante, con frecuencia, para comprender la interna estructuración de los vínculos de la solidaridad, ayudan, pero no bastan para el sentido de la responsabilidad en temas cruciales y arduos. Lo que un hombre responsable necesita saber es el signo bueno o malo de los vínculos de solidaridad con que se halla entrelazado, esto es, los principios a que se debe atener para establecer sus lazos sociales. $Y$ una vez que se encuentra asociado a los hombres, cómo debe pensar y juzgar de ellos y de sus cosas, para adoptar la actitud conveniente. La filosofía cristiana cultivó desde sus comienzos el estudio de las leyes internas quo deben presidir las diversas formaciones de responsabilidad a que el hombre pertenece en su convivencia (13).

(12) Hay que distinguir entre el amor-acción o impulso del afecto $y$ el amor en término. La voz del amor no sólo significa acción, sino también el término producido por la acción.

(13). La Filosotía antigua ni planteó ni resolvió esta dificultad. Platón y Aristóteles concibieron una sociedad desarticulada en clases $y$ dividida en partes. Los estoicas hallaron la Conciliatio, sin formulár leyes internas ni criterios. Cicerón y Séneca se contentan con identidad de especie para unir mutuamente a los hombres. San Agustín consigna la división profunda entre los hombres y de sus agrupaciones en buenas $y$ malas (visión cristiana do las dos ciudades). 


\section{Principios de la solidaridad.}

Hagamos, al menos, una revisión de los principios fundamentales do Ia solidaridad.

Hállase el primero diciendo que la solidaridad entre dos seres es tanto mayor cuanto uno recibe más de la acción del otro, o de él más depende. Tal la relación con Dios, íntima, como Causa de la crectura, ya que no puede haber mayor solidaridad que la del ser. La solidaridad con el Creador es irrompible, aún en los seres que moralmente se hayan distanciado de él para siempre. La creación es algo que simultáneamente emana de Dios y se recibe en la creatura como sin eslabón intermedio alguno: la dependencia no cesa con la creación en su momento, sino que es una acción transeúnte y permanente, que persevera conservando al ser creado; la dependencia creativa, en cuanto acción, no es acción accidental como la que necesita de sujeto, sino que es acción sustancial; entre dos seres, no cabe mayor solidaridad que esta dependencia sustancial (14).

En segundo lugar, no hay solidaridad sin alteridad total e interacción-de los seres solidariamente unidos; la naturaleza de la solidaridad consiste en unidad de acción, no es en unidad entitativa. Es unidad de acción y no de agentes. En el orden sobrenatural, la unidad de acción se obtiene por la potencia obediencial activa (15).

Sustancial o accidental, la solidaridad tiene su norma y criterio en la solidaridad de la creatura con Dios. Todas las conexiones de solidaridad entre seres creados son participación de la solidaridad que tienen con Dios, y por tanto, le son tributarias y complementarias; aún la misma solidaridad entre el alma y el cuerpo del hombre. De aquí la regla fundamental de que los vínculos sociales tiendan a la máxima unidad de acción y al respeto máximo de la distinción de persona.

La solidaridad fundamental con el creador es también la base para resolver los conflictos en los casos de concurrencia de diversas obligaciones de solidaridad que solicitan a una misma persona en sentidos contrarios: la preferencia debe atribuirse a aquel ser cuya conexión es más favorable a la actividad característica y perfectiva del ser; los lazos constitutivos de una solidaridad accidental meramente operativa y el fin a que se enderezan, no deben tener otra razón de ser que la de perfeccionar la acción de los seres solidarios, y mediante la acción, su naturaleza y esencia.

Lo que en la acción creativa es acción substancial y permanente, en la actividad occidental debe ser sistematización jerarquizada de los vínculos de solidaridad. Esta sistematización debe aplicarse a los vínculos del indi-

(14) A esta unión podríamos llamar unión hypostática, en un sentido fllosófico anterior al concepto trinitario cristiano.

(15) En todo orden se podrían distinguir dos clases de solidaridad operativa; una, llamada causalidad estructural $y$ otra, causalidad funcional. La primera es para constituir un conjunto solidario, y la segunda para aetuar dentro de dicho conjunto (efr. Gómez Árboleya, Sociología, Escuela de Humanismo; en Rev. de Ets. Políticos, Ne 79, 1955, pág. 22. 
viduo en la solidaridad familiar, eclesiástica y civil. Hay otras conexiones secundarias y potestativas que, en número indefinidamente grande, puede establecer el individuo, pero siempre bajo el mismo principio fundamental apoyado en el fin esencial a toda solidaridad. Los vínculos de solidaridad que no pueden ser participaciones de la primera, no son vínculos verdoderos, sino falsificaciones de la verdadera solidaridad. Aún accidental, toda solidaridad tiene que ser en alguna manera sustancial; lo que no puede ser por naturaleza y propiamente, podrá serlo por procedimientos sistemáticos basados en la naturaleza, y por tanto legítimos.

Aplicación de los principios.

Apliquemos estos principios. Una sociedad amorfa y anórquica es un conglomerado de formas, un ente por accidente; cuando la sociedad posee una autoridad respetada por el pueblo, éste constituye y exige que se le considere como ente en sí; los demás estados deben otorgarle el reconocimiento de hecho; finalmente, cuando la sociedad organizada es capaz de responsabilidades, debe otorgársele el reconocimiento de derecho. $\mathrm{Si}$ estos principios obligan en justicia al reconocimiento de entidades que se forman de nuevo, con más justicia obligan a la no destrucción de formas: existentes. Esto vale para toda persona moral.

Las instituciones públicas y canónicas subaltemas, reciben también su fuerza de estatutos aprobados por la autoridad eclesióstica o civil. Pero no cualquier conglomerado social puede adquirir esta estructura entitativa. El vicio del positivismo ha consistido en no saber discriminar los hechos en su diversa graduación ontológica. En la frondosa selva de agrupaciones de tipo privado y arbitrario, es donde se presentan estructuras que no cumplen los pre-requisitos de una solidaridad perfecta del individuo; estas no son verdaderas asociaciones, si deben obtener reconocimiento de tales.

Dentro de esta falsa solidaridad podemos distinguir dos grupos. Al primero pertenecen las creaciones sociales arbitrarias, de grandes masas que se coaligan o agrupan como ejércitos sin bandera y sin finalidad precisable. Entre ellas, la solidaridad que con criterios positivistas se atribuye a la ingente multitud del mundo obrero o a la juventud internacional organizada en un frente único. $Y$ por análogas razones, resulta disolvente $Y^{*}$ destructiva la falsa solidaridad de las sociedades secretas, cuyos componentes mediatizan su personalidad en aras de un poder que actúa al margen del interés común; una vinculación contraria a la solidaridad primera $Y$ fundamental, de la que procede toda fuerza unitiva, es lógicamente contraria a la misma sociedad humana, y no puede aspirar a crear entre sus miembros, el sentido de responsabilidad característico del hombre.

Semejante al vicio de los nexos sociales arbitrarios es para la práctica; su estructuración antinatural y desordenada. Basta en una sociedad asignar a los derechos de los miembros la jerarquía que corresponde a los deberes, para desnaturalizarla y sofocar el sentido de la responsabilidad; la tergiversación del deber en el derecho tiene lugar especialmente en las actividades 
rectoras y docentes, civiles y religiosas. Así, si la autoridad se considera como un derecho al mando y no como servicio público, surge automáticamente el juego de las ambiciones, y con ellas los conflictos de jurisdicción y la lucha por el poder; así la autoridad establecida por Dios para servir $\alpha$ la solidaridad de los hombres, se transforma en tributo exigido al pueblo en aras del dios Estado, o de la ambición política en sus infinitas especies.

En el campo de la ciencia y de la enseñanza surgen con frecuencia análogos conflictos. Rara vez se lucha por el cumplimiento del deber social de enseñar. Lo ordinario es que las disensiones y pleitos provengan de las ambiciones 0 aspiraciones económicas que pueden llevar signo justo 0 injusto. En todo caso, el sentido de la responsabilidad exige que no se subordine a la lucha política una organización eminentemente social; aplicar a la Universidad $y_{0}$ otras instituciones docentes públicas un criterio político $y$ egoísta, sería transformar en elementos de discordia los más altos deberes de solidaridad y unión; el más elemental sentido de la responsabilidad debeestar suficientemente desarrollado paro no incurrir en tal desorden. 